\title{
KEANEKARAGAMAN JENIS POHON PENYUSUN VEGETASI DI HUTAN RAWA GAMBUT PADA KAWASAN HUTAN LINDUNG GUNUNG AMBAWANG KECAMATAN KUBU KABUPATEN KUBU RAYA
}

\author{
(Tree Species Diversity Of Vegetation Composition In The Peat Swamp Forest In The Gunung \\ Ambawang Protected Forest Area Of Kubu Raya Sub-District Of Kubu Raya Regency)
}

\author{
Bayu Aji Prasetyo, Togar Fernando Manurung, Hafiz Ardian \\ Fakultas Kehutanan Universitas Tanjungpura Jl. Daya Nasional, Pontianak 78124 \\ E-mail : ap_bayu@yahoo.co.id
}

\begin{abstract}
Peatland is a weatland ecosystem formed by the accumulation of organic matter on the forest floor from the debris of the vegetation above it for a long time. This process occurs because of the slow rate of decomposition compared to the rate of deposition of organic matter on the wet/inundated forest floor. This study aims to determine the vegetation species diversity found in the peat swamp forest of the area of Gunung Ambawang protected forest in Kubu SubDistrict of Kubu Raya Regency. The method used in this study is a plot method with the initial determination of the plot carried out through purposive sampling then the other plots were carried out by systematic sampling. Observation of forest compositionwas made in 5 (five) observation plots, with a length of $200 \mathrm{~m}$, width of each plot being $20 \mathrm{~m}$ and distance between plots $100 \mathrm{~m}$. The research found 39 species of vegetation dominated by medang species (Litsea sp) of the Lauraceae family, which is the most common vegetation found in the peat swamp forest area in the protected forest og Gunung Ambawang.
\end{abstract}

Keywords: peat swamp forest, protection forest, species diversity

\section{PENDAHULUAN}

Alikodra (1990) menjelaskan bahwa keanekaragaman jenis dapat ditemukan pada keanekaragaman hayati, yaitu tempat terdapatnya berbagai macam variasi bentuk, penampilan, jumlah dan sifat makhluk yang terdapat pada tingkat ekosistem, tingkat jenis dan tingkat genetika.

Daerah tropis basah memiliki keanekaragaman jenis tumbuhan dan hewan yang tinggi karena pada daerah tropis jenis iklim dan kondisi geologi yang khusus, yaitu adanya musim kemarau dan musim penghujan setiap tahunnya Alikodra (1990).
Hutan adalah suatu kesatuan ekosistem berupa hamparan berisi sumber daya alam hayati yang didominasi pepohonan dalam persekutuan, yang satu dengan lainnya tidak dapat dipisahkan (Departemen Kehutanan, 1999). Kerusakan hutan dapat disebabkan oleh segala aktivitas manusia seperti penebangan liar, ladang berpindah, kebakaran hutan dan pembukaan perkebunan. Ekosistem di hutan rawa gambut pada kawasan Hutan Lindung Gunung Ambawang telah mengalami kerusakan akibat dari kegiatan manusia, diantaranya kegiatan penebangan dan kegiatan alih fungsi lahan. Tujuan dari penelitian ini adalah 
untuk mendata keanekaragaman jenis vegetasi yang terdapat di hutan rawa gambut pada kawasan Hutan Lindung Gunung Ambawang Kecamatan Kubu Kabupaten Kubu Raya.

\section{METODE PENELITIAN}

Penelitian ini dilaksanakan pada kawasan hutan rawa gambut pada kawasan hutan lindung gunung Ambawang Kecamatan Kubu Kabupaten Kubu Raya dengan luasan hutan 14.65 Ha. Waktu untuk penelitian dan analisis data dilakukan selama lebih kurang 4 (empat) minggu, mulai dari tanggal 13 Desember 2014 sampai 10 Januari 2015.

Metode yang digunakan dalah metode jalur berpetak. Petak pengamatan diletakkan secara purposive sampling, dengan asumsi vegetasi yang ada dapat mewakili seluruh komunitas vegetasi di kawasan hutan rawa gambut pada kawasan hutan lindung gunung Ambawang Kecamatan Kubu Kabupaten Kubu Raya. Gambar 1.

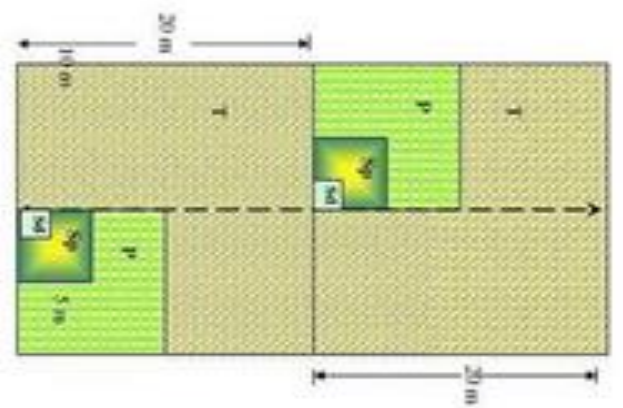

Gambar 1. Petak pengamatan berdasarkan (Kusmana C, 1997). (Observation plots based on Kusmana C, 1997)

Lokasi yang diteliti dibuat 5 (lima) jalur pengamatan dengan panjang 200 $\mathrm{m}$ dengan lebar tiap jalur $20 \mathrm{~m}$ dan jarak antar jalur $100 \mathrm{~m}$, dambil data semai (2x2), pancang $(5 \times 5)$, tiang $(10 \times 10)$ dan pohon (20x20).

a. Indeks Nilai Penting (INP)

Indeks nilai penting diperoleh dari penjumlahan kerapatan relatif, frekuensi relatif, untuk mendapatkan nilai-nilai tersebut digunakan rumus perhitungan analisis vegetasi menurut Soerianegara dan Indrawan (1988) sebagai berikut :

1. Kerapatan (K) dan Kerapatan Relatif (KR) diperoleh dengan menggunakan rumus sebagai berikut

$$
\begin{aligned}
& \mathrm{K}=\frac{\text { Jumlah individu suatu jenis }}{\text { Luas contoh }} \\
& \mathrm{KR}=\frac{\text { Kerapatan dari suatu jenis }}{\text { Kerapatan seluruh jenis }} \mathrm{X}
\end{aligned}
$$
$100 \%$

2. Frekuensi (F) dan Frekuensi Relatif (FR) diperoleh dengan menggunakan rumus sebagai berikut : $\mathrm{F}=$

$\underline{\text { jumlah petak ditemukannya suatu jenis }}$ jumlah petak seluruhnya

$$
\mathrm{FR}=\frac{\text { frekuensi suatu jenis }}{\text { frekuensi seluruh jenis }} \times 100 \%
$$

3. Persen Penutup (C) dan Penutupan Relatif (CR) diperoleh dengan menggunakan rumus sebagai berikut 


$$
\begin{aligned}
& \mathrm{C}=\frac{\text { Jumlah luas bidang dasar pohon }}{\text { Luas total areal contoh }} \\
& \mathrm{CR}=\frac{\text { Persen penutup suatu jenis }}{\text { Total seluruh jenis }}
\end{aligned}
$$

4. Indeks Nilai Penting (INP) $=\mathrm{KR}+$ $\mathrm{FR}+\mathrm{CR}$

5. Indeks Dominansi $(C)$ diperoleh dengan menggunakan rumus Simpson (1949) dan Indeks Keanekaragaman Jenis $(\mathrm{H})$ menggunakan rumus ShannonWiener dalam Indriyanto (2006) sebagai berikut:

$$
\mathrm{C}=\Sigma\left(\frac{n i(n i-1)}{N(N-1)}\right) \text { dan }
$$

$\mathrm{H}=-\Sigma\left\{\left(\frac{n i}{N}\right) \log \left(\frac{n i}{N}\right)\right\}$

Keterangan :

$\mathrm{C}=$ Indeks Dominansi

$\mathrm{H}=$ Indeks Keanekaragaman

Shannon

n. $\mathrm{i}=$ Indeks nilai penting spesies ke-i

$\mathrm{N}=$ Jumlah indeks nilai penting

seluruh

Spesies

\section{HASIL DAN PEMBAHASAN}

Berdasarkan hasil penelitian ditemukan 39 jenis vegetasi untuk semua tingkat pertumbuhan yang meliputi tingkat semai, tingkat pancang, tingkat tiang dan tingkat pohon. Tabel 1 .

Tabel 1. Jenis-jenis vegetasi hutan rawa gambut pada kawasan hutan lindung gunung Ambawang Kecamatan Kubu Kabupaten Kubu Raya (The type

\begin{tabular}{|c|c|c|c|}
\hline Family & No & Nama Lokal & Nama Latin \\
\hline Anacardiaceae & 1 & Rengas & Gluta renghas. \\
\hline \multirow[t]{2}{*}{ Apocynaceae } & 2 & Pulai & Alstonia scholaris $(\mathrm{L})$ \\
\hline & 3 & Jelutung & Dyera lowii. \\
\hline Bombacaceae & 4 & Durian burung & Durio carinatus Mast. \\
\hline Caesalpiniaceae & 5 & Kempas & Koompassia sp. \\
\hline Cannabaceae & 6 & Keminting & Trema tomentosa (Roxb.) H. Hara. \\
\hline Crypteroniaceae & 7 & Mentibuk & Dactylocladus stenostachys Oliver. \\
\hline Dipterocarpaceae & 8 & Meranti & Shorea $\mathrm{sp}$ \\
\hline \multirow[t]{2}{*}{ Dilleniaceae } & 9 & Semprat & Dracontomelon spp \\
\hline & 10 & Simpur & Dillenia excelsa Gilg. \\
\hline Ebenaceae & 11 & Kayu malam & Diospyros macrophylla $\mathrm{Bl}$. \\
\hline \multirow[t]{2}{*}{ Euphorbiaceae } & 12 & Mahang & Macaranga hosei \\
\hline & 13 & Kareke & Elateriosp ermum topas BI \\
\hline Fabaceae & 14 & Arak & Kompassia malaccensis Maing.ex \\
\hline Guttiferae & 15 & Bintangor & Calophyllum obliquinervium Merr. \\
\hline Hypericaceae & 16 & Gerunggang & Cratoxylum glaucum Korth. \\
\hline Icacinaceae & 17 & Pasir-pasir & Stemonurus secundiflorus Blume. \\
\hline \multirow[t]{5}{*}{ Lauraceae } & 18 & Belian & Eusideroxylon zwageri. \\
\hline & 19 & Medang & Litsea $\mathrm{sp}$. \\
\hline & 20 & Medang bambu & Litsea odorifera \\
\hline & 21 & Medang keladi & Alseodaphne sp. \\
\hline & 22 & Medang lendir & Alseodaphne umbelliflora \\
\hline
\end{tabular}
of vegetation in the peat swamp forest area in the Gunung Ambawang Protected Forest of Kubu Sub-District of Kubu Raya Regency) 


\begin{tabular}{llll} 
Leeaceae & 23 & Tali-tali & Leeaindica. \\
Meliaceae & 24 & Parak & Amoorarubiginosa Hiern. \\
Moraceae & 25 & Cempedak air & Artocarpus teysmanni Miq. \\
Myrtaceae & 26 & Jambu-jambu & Syzygium sp. \\
& 27 & Gelam tikus & Syzygium zeylanicum. \\
Myristicaeae & 28 & Pendarah & Myristicalowiana. \\
Rosaceae & 29 & Ilas & Parastemon urophyllum. \\
Rubiaceae & 30 & Jabon & Anthocephalus cadamba (Roxb.) Miq. \\
Rutaceae & 31 & Kemuning & Murraya paniculata Jack. \\
Sapindaceae & 32 & Kasai & Pometia alnifolia (Bl.) King. \\
& 33 & Rambutan & Nephelium lappaceum L. \\
Sapotaceae & 34 & Nyatoh & Payenalerii. \\
& 35 & Nyatoh ketiau & Madhuca motleyana \\
Thymelaeaceae & 36 & Ramin & Gonystylus bancanus Kurz. \\
NN & 37 & Gedebok & NN \\
NN & 38 & Jangkar tinggi & NN \\
NN & 39 & Kelam ijo & NN \\
\hline
\end{tabular}

Berdasarkan hasil analisis data hasil yang didapat untuk indeks keanekaragaman jenis tiap tingkatan pertumbuhan vegetasi yaitu, untuk vegetasi tingkat semai adalah 0.88 , tingkat pancang adalah 0.87 , tingkat tiang adalah 0.91 sedangkan tingkat pohon adalah 0.94. Tabel 1 Indeks Keanekaragaman Jenis pada

Tabel 1. Daftar jumlah jenis dan jumlah individu jenis vegetasi untuk tingkat semai, pancang, tiang dan pohon yang ditemukan di kawasan hutan rawa gambut pada kawasan Hutan Lindung Gunung Ambawang Kecamatan Kubu Kabupaten Kubu Raya (List of the number of species and number of individual vegetation species for seedling, saplings, poles and trees found in the peat swamp forest area in the Gunung Ambawang Protected Forest of Kubu Sub-District of Kubu Raya Regency)

\begin{tabular}{cccccc}
\hline No & $\begin{array}{c}\text { Tingkat } \\
\text { Pertumbuhan }\end{array}$ & $\begin{array}{c}\text { Jumlah } \\
\text { Jenis }\end{array}$ & $\begin{array}{c}\text { Jumlah } \\
\text { Individu }\end{array}$ & C & H \\
\hline 1 & Semai & 22 & 857 & 0.11 & 0.88 \\
2 & Pancang & 27 & 505 & 0.12 & 0.87 \\
3 & Tiang & 32 & 278 & 0.08 & 0.91 \\
4 & Pohon & 28 & 115 & 0.06 & 0.94 \\
\hline
\end{tabular}

Jenis yang mendominasi pada tingkat semai di kawasan hutan lindung gunung Ambawang adalah jambujambu (Syzygium sp) dengan INP 32.55\%, kemuning (Murraya paniculata Jack) dengan INP 31.34\%, medang (Litsea $s p$ ) dengan INP 23.27\%, gelam tikus (Syzygium zeylanicum) dengan INP $22.55 \%$, pasir- pasir (Stemonurus Secundiflorus Blume) dengan INP $18.25 \%$. Jenis ini memiliki keanekaragaman tinggi karena tingkat pertumbuhan beradaptasi dengan lingkungan di wilayah hutan rawa gambut sehingga terpenuhi ruang, nutrisi dan sinar matahari bagi pertumbuhan vegetasi. Tabel 2. 
Tabel 2. Tujuh jenis tumbuhan dominan kelompok semai (Seven dominant plant species of seedling grop)

\begin{tabular}{clccccccc}
\hline NO & JENIS & INDIVIDU & K & KR \% & F & FR \% & INP \% & C \\
\hline 1 & Jambu - jambu & 157 & 7850 & 18.31 & 0.74 & 14.23 & 32.55 & 0.03 \\
2 & Kemuning & 150 & 7500 & 17.50 & 0.72 & 13.84 & 31.34 & 0.03 \\
3 & Medang & 94 & 4700 & 10.96 & 0.64 & 12.30 & 23.27 & 0.01 \\
4 & Gelam tikus & 101 & 5050 & 11.78 & 0.56 & 10.76 & 22.55 & 0.01 \\
5 & Kemuning & 150 & 7500 & 17.50 & 0.72 & 13.84 & 31.34 & 0.03 \\
6 & Pasir-pasir & 74 & 3700 & 8.63 & 0.5 & 9.61 & 18.25 & 0.00 \\
7 & Semprat & 58 & 2900 & 6.76 & 0.28 & 5.38 & 12.15 & 0.0045 \\
\hline
\end{tabular}

Pada tingkat pancang yang mendominasi adalah adalah jambujambu (Syzygium sp) dengan INP $60.04 \%$, medang (Litsea sp) dengan INP 49.39\%, kemuning (Murraya paniculata Jack) dengan INP $31.74 \%$, pasir-pasir (Stemonurus secundiflorus
Blume) dengan INP 27.68\%, gelam tikus (Syzygium zeylanicum) dengan INP $16.60 \%$. Dominasi individu pada tingkat pancang banyak tersebar dan mumpunyai jumlah pertumbuhan yang stabil dan berkembang secara merata pada wilayah penelitian. Tabel 3 .

Table 3. Tujuh jenis tumbuhan dominan kelompok pancang (Seven dominant plant species of sapling grop)

\begin{tabular}{|c|c|c|c|c|c|c|c|c|c|c|}
\hline No & JENIS & INDIVIDU & $\mathbf{K}$ & $\begin{array}{c}\text { KR } \\
\%\end{array}$ & $\mathbf{F}$ & $\begin{array}{c}\text { FR } \\
\%\end{array}$ & C & CR & $\begin{array}{c}\text { INP } \\
\%\end{array}$ & C \\
\hline 1 & Jambu-jambu & 130 & 1040 & 25.74 & 0.72 & 15.92 & 1.25 & 18.36 & 60.04 & 0.06 \\
\hline 2 & Medang & 89 & 712 & 17.62 & 0.62 & 13.71 & 1.23 & 18.05 & 49.39 & 0.03 \\
\hline 3 & Kemuning & 59 & 472 & 11.68 & 0.4 & 8.84 & 0.7 & 11.20 & 31.74 & 0.01 \\
\hline 4 & Pasir-pasir & 42 & 336 & 8.31 & 0.36 & 7.96 & 0.77 & 11.40 & 27.68 & 0.0068 \\
\hline 5 & Mahang & 5 & 40 & 0.99 & 0.04 & 0.88 & 0.07 & 1.16 & 3.03 & \\
\hline 6 & Ilas & 11 & 88 & 2.17 & 0.16 & 3.53 & 0.24 & 3.56 & 9.28 & 0.0004 \\
\hline 7 & Jelutung & 9 & 72 & 1.78 & 0.14 & 3.09 & 0.15 & 2.21 & 7.09 & 0.0003 \\
\hline & Pada & tingkat & tiang & yang & \multirow{7}{*}{\multicolumn{6}{|c|}{$\begin{array}{l}\text { kempas (Koompassia sp) dengan INP } \\
18.62 \% \text {. Komposisi tegakan banyak } \\
\text { tersebar di lokasi penelitian sehingga } \\
\text { tingkat pertumbuhan tegakan menjadi } \\
\text { melimpah dan meningkatkan jumah } \\
\text { keanekaragaman jenis tumbuhan. Tabel } \\
\text { 4. }\end{array}$}} \\
\hline & \multirow{5}{*}{\multicolumn{4}{|c|}{$\begin{array}{l}\text { mendominasi adalah medang (Litsea } s p \text { ) } \\
\text { dengan INP } 66.26 \% \text {, pasir-pasir } \\
\text { (Stemonurus secundiflorus Blume) } \\
\text { dengan INP } 21.85 \% \text {, meranti (Shorea } \\
\text { sp) dengan INP } 19.11 \% \text {, jambu-jambu }\end{array}$}} & & & & & & \\
\hline & & & & & & & & & & \\
\hline & & & & & & & & & & \\
\hline & & & & & & & & & & \\
\hline & & & & & & & & & & \\
\hline & (Syzygium s & ) dengan & 1 & $.79 \%$ & & & & & & \\
\hline
\end{tabular}


Tabel 4. Tujuh jenis tumbuhan dominan kelompok tiang (Seven dominant plant species of pole grop)

\begin{tabular}{|c|c|c|c|c|c|c|c|c|c|c|}
\hline NO & JENIS & INDIVIDU & $\mathbf{K}$ & $\begin{array}{c}\text { KR } \\
\%\end{array}$ & $\mathbf{F}$ & $\begin{array}{c}\text { FR } \\
\%\end{array}$ & C & CR & $\begin{array}{c}\text { INP } \\
\%\end{array}$ & $\mathbf{C}$ \\
\hline 1 & Medang & 66 & 132 & 23.74 & 0.6 & 17.12 & 1.64 & 25.39 & 66.26 & 0.055 \\
\hline 2 & Pasir-pasir & 21 & 42 & 7.55 & 0.22 & 6.07 & 0.53 & 8.22 & 21.85 & 0.005 \\
\hline 3 & Meranti & 15 & 30 & 5.39 & 0.24 & 6.62 & 0.45 & 7.09 & 19.11 & 0.002 \\
\hline 4 & Jambu-jambu & 17 & 34 & 6.11 & 0.26 & 7.18 & 0.35 & 5.49 & 18.79 & 0.003 \\
\hline 5 & Kempas & 18 & 36 & 6.47 & 0.22 & 6.07 & 0.39 & 6.07 & 18.62 & 0.004 \\
\hline 6 & Gelam tikus & 8 & 16 & 2.87 & 0.14 & 3.86 & 0.21 & 3.26 & 10.00 & 0.0007 \\
\hline 7 & Rambutan & 15 & 30 & 5.39 & 0.26 & 7.18 & 0.37 & 5.76 & 18.34 & 0.0027 \\
\hline
\end{tabular}

Pada tingkat pohon yang mendominasi kempas (Koompassia sp) dengan INP $44.22 \%$, medang (Litsea sp) dengan INP $37.83 \%$, jambu-jambu (Syzygium sp) dengan INP 20.65\%, rambutan (Nephelium lappaceum L) dengan INP $19.36 \%$, ilas (Parastemonurophyllum) dengan INP
$15.03 \%$. Terdapatnya pohon-pohon yang besar mendukung tingkat pertumbuhan perkembangan keanekaragaman jenis secara alami, sehingga dapat beregenerasi lebih tinggi dan meningkatkan jumlah individu vegetasi. Tabel 5 .

Tabel 5. Tujuh jenis tumbuhan dominan kelompok pohon (Seven dominant plant species of tree grop)

\begin{tabular}{llccccccccr}
\hline NO & \multirow{2}{*}{ JENIS } & \multirow{2}{*}{ INDIVIDU } & $\mathbf{K}$ & $\begin{array}{c}\text { KR } \\
\mathbf{\%}\end{array}$ & $\mathbf{F}$ & $\begin{array}{c}\text { FR } \\
\boldsymbol{\%}\end{array}$ & $\mathbf{C}$ & $\mathbf{C R}$ & $\begin{array}{c}\text { INP } \\
\boldsymbol{\%}\end{array}$ & $\mathbf{C}$ \\
\hline 1 & Kempas & 18 & 9 & 15.65 & 0.28 & 13.86 & 0.42 & 14.71 & 44.22 & 0.02 \\
2 & Medang & 16 & 8 & 13.91 & 0.28 & 13.86 & 0.28 & 10.05 & 37.83 & 0.01 \\
3 & Jambu-jambu & 9 & 4.5 & 7.82 & 0.14 & 6.93 & 0.16 & 5.89 & 20.65 & 0.005 \\
4 & Rambutan & 8 & 4 & 6.95 & 0.12 & 5.94 & 0.18 & 6.46 & 19.36 & 0.004 \\
5 & Meranti & 4 & 2 & 3.47 & 0.08 & 3.96 & 0.11 & 4.16 & 11.60 & - \\
6 & Keminting & 4 & 2 & 3.47 & 0.08 & 3.96 & 0.17 & 6.10 & 13.54 & - \\
7 & Kayu Malam & 7 & 3.5 & 6.08 & 0.12 & 5.94 & 0.19 & 6.61 & 18.63 & 0.003 \\
\hline
\end{tabular}

Hasil analisis data nilai Indeks

Dominansi untuk tingkat semai adalah 0.11, tingkat pancang adalah 0.12 , tingkat tiang adalah 0.08 sedangkan tingkat pohon adalah 0.06. Secara keseluruhan dapat dilihat nilai indeks dominansi (C) pada lokasi penelitian termasuk rendah, karena nilai dominansi dari semua tingkat pertumbuhan belum mencapai nilai indeks dominansi tertinggi $(\mathrm{C}=1)$. Hal menyebabkan tingkat pertumbuhan keanekaragaman jenis yang terhambat oleh aktivitas penebangan liar yang dilakukan masyarakat sekitar hutan dan areal perkebunan yang berada disekitar areal hutan rawa gambut. Pertumbuhan jenis tumbuhan untuk vegetasi Medang (Litsea sp) mendominasi disemua tingkat kehidupan, ini menandakan bahwa dominasi jenis ini menguasai seluruh wilayah penelitian.

Berdasarkan hasil analisis data nilai indeks keanekaragaman jenis pada tingkat semai, pancang, tiang dan pohon (Tabel 1) termasuk rendah karena nilainya kurang dari $1(\mathrm{H}<1)$. Hal ini kemudian kriteria dilakukan oleh Odum (1993) Indeks keanekaragaman (H) merupakan suatu angka yang tidak memiliki satuan dengan kisaran 0-3. Tingkat keanekaragaman akan tinggi 
jika nilai $\mathrm{H}$ mendekati 3 , sehingga hal ini menunjukkan kondisi komunitas baik. Sebaliknya jika nilai $\mathrm{H}$ mendekati 0 maka keanekaragaman rendah dan kondisi komunitas kurang baik. Kondisi ini diperjelas dalam hasil penelitian yang menunjukkan bahwa tingkat keanekaragaman yang diperoleh dari hasil analisis data rendah.

\section{Kesimpulan}

Berdasarkan hasil penelitian diketahui bahwa pada semua tingkat pertumbuhan jenis yang memiliki jumlah paling dominan adalah family Lauraceae yaitu Medang (Litsea sp).

Keanekaragaman jenis yang terdapat pada Hutan Lindung Gunung Ambawang menjadi salah satu kawasan hutan yang memiliki potensi besar untuk konservasi jenis tumbuhan di Kalimantan Barat.

\section{Saran}

Perlu dilakukannya pembinaan dan penyuluhan terhadap masyarakat yang berada di kawasan hutan lindung Gunung Ambawang untuk menumbuhkan rasa kepedulian terhadap kelestarian.
Perlu dilakukan penanaman pohon terhadap lahan-lahan kosong yang berguna bagi perlindungan tanah agar terhindar dari erosi dan banjir.

\section{DAFTAR PUSTAKA}

Alikodra, H. S. 1990. Erosi Keanekaragaman Jenis. Rineka Cipta. Jakarta.

Departemen Kehutanan. 1990. Undangundang Republik Indonesia Nomor 41 Tahun 1999 Tentang Kehutanan. Jakarta.

Indriyanto. 2006. Ekologi Hutan. Jakarta : PT. Bumi Aksara.

Kusmana, C. 1997. Metode Survey Vegetasi. PT. Penerbit Institut Pertanian Bogor. Bogor.

Odum, 1993. Dasar-Dasar Ekologi. Terjemahan Tjahjono. Samingan. Gajahmada. University Pres. Yogyakarta.

Simpson, E.H. 1949. Measurement of Diversity. Nature Science. USA.
Soerianegara I.,dan A.Indrawan, 1988.Ekologi Hutan Indonesia. Departemen Managemen Hutan. Fakultas Kehutanan.IPB. Bogor: 